\title{
Caracterização da resposta imunológica da lesão pulmonar causada pelo vírus H1N1
}

\author{
Acadêmica: Marina Ballarin Albino \\ Orientadores: Monique Buttignol, Marisa Dolhnikoff, Thais Mauad
}

Introdução: O inverno de 2009 foi marcado pelo surgimento de um novo subtipo do vírus da influenza A subtipo H1N1, identificado no México e circulante em vários países do mundo, caracterizando nova pandemia. No estado de São Paulo, em 2009, a incidência de Síndrome do Desconforto Respiratório Agudo (SDRA) pelo vírus H1N1 foi de 15,17 casos para cada 100 mil habitantes. Poucos estudos abordaram aspectos imunes do tecido pulmonar em pacientes com formas graves da doença. Hipotetizamos que nos casos fatais de infecção existe aumento de células do sistema imune inato e de células linfocitárias T regulatórias nos pulmões destes pacientes.

Objetivo: Verificar se a densidade de mastócitos (quimase), linfócitos B (CD20+) e células dendríticas maduras (CD83) em pulmões de pacientes que faleceram de SDRA pela infecção do vírus H1N1 pandêmico difere quando comparada a pulmões normais ou de SDRA de etiologia extra-pulmonar.

Metodologia: Analisamos tecido pulmonar de 3 grupos de pacientes divididos em: 1) SDRA indireta - 14 pacientes falecidos por SDRA não pulmonar; 2) H1N1 - 16 pacientes falecidos por SDRA pelo vírus H1N1; 3) Controle -16 paciente falecidos por causas extra-pulmonares, sem alterações histológicas pulmonares. Cortes de $5 \mu \mathrm{m}$ do tecido pulmonar foram submetidos a reações imunohistoquímicas. As lâminas foram escaneadas e as imagens transferidas para o software Image-Pro Plus 4.1. Foram quantificadas densidades celulares de cada marcador no tecido alveolar. Os dados numéricos (cels/ comprimento) foram apresentados como mediana (intervalo interquartil) de acordo com a distribuição dos resultados. A análise estatística foi calculada com testes de comparações múltiplas entre as médias de cada grupo utilizando-se o teste “One way ANOVA" com pós-teste "Bonferroni”. O nível de significância considerado foi $\leq 5 \%$.

Resultados: Em relação às células B CD20+ e aos mastócitos verificamos que não houve diferença entre os grupos: Linfocitos B CD20+ (Controle 0,63 [0,62], ARDS 0,52 [0,58], H1N1 0,73 [0,61] células/mm) e Mastócitos: (Controle 0,52 [0,82], ARDS 0,64 [0,77], H1N1 0,88 [1,18] células/mm). Com relação às células CD 83+, a densidade de células dendríticas maduras é maior no grupo H1N1 quando comparado ao controle (Controle 0,54 [0,47], ARDS 0,79 [0,84], H1N1 1,45 [1,07] células/mm; $\mathrm{p}=0.007)$.

Discussão e conclusão: Em nosso estudo, não encontramos diferença na densidade de mastócitos (quimase) no tecido pulmonar dos pacientes nos diferentes grupos, semelhante a escassa literatura disponível no assunto. Verificamos aumento de células dendríticas maduras (CD83) no grupo H1N1, quando comparado ao controle. Modelos prévios demonstraram aumento no número de células dendríticas e de linfócitos T CD8 poucas horas após exposição ao vírus influenza. Com relação aos linfócitos B CD20+, não encontramos diferenças entre os grupos. Possivelmente, nas doenças intersticiais agudas, não há tempo suficiente para o recrutamento desses linfócitos. No entanto, avaliamos apenas o parênquima pulmonar e não os agregados linfoides peribronquiolares onde normalmente estas células estão localizadas, mas que são geralmente incomuns neste tipo de lesão aguda. Concluindo, pacientes que apresentaram SDRA de etiologia pulmonar pelo H1N1 apresentaram maior densidade de células dendríticas no parênquima pulmonar comparado a indivíduos normais. 